\title{
UM ESTUDO SOBRE MULHERES IDOSAS NO MERCADO DE TRABALHO, NO MUNICÍPIO DE SÃO JOSÉ DOS CAMPOS (SP)
}

\author{
Amanda Cerquearo Rodrigues dos Santos ${ }^{1}$ \\ Anna Clara Mendes Gonçales ${ }^{2}$ \\ Heloísa de Morais Ramos ${ }^{3}$ \\ Érica Reis Costa Carvalho ${ }^{4}$
}

Resumo: A Terceira Idade necessita de uma atividade para permanecer ativa, seja essa, uma atividade remunerada ou até mesmo alguma participação em espaços coletivos. É imprescindível um trabalho à pessoa idosa para ajustar suas relações sociais e possibilitar novos relacionamentos, para suprir as perdas adquiridas ao longo da vida. Este trabalho tem por objetivo realizar um estudo com uma parcela de mulheres idosas do município de São José dos Campos (SP), para verificar a sua participação em atividades econômicas. Foram realizadas pesquisas em fonte secundárias e primárias para observar e analisar o perfil e o motivo das mulheres idosas estarem inseridas, ou não, no mercado de trabalho. Verificou-se que após a aposentadoria a maioria das mulheres idosas deixam de exercer atividade remunerada no mercado formal, sendo que são a minoria as que atuam na formalidade. Conclui-se que a mulher idosa do município de São José dos Campos (SP) não se sente inserida no mercado de trabalho e as que estão é por necessidade elou reforço de renda familiar.

Palavras-chave: Terceira Idade; Mulheres; Mercado de Trabalho.

\footnotetext{
1 Técnico em Administração/Univap, Brasil. E-mail: amandacerq.cunha@hotmail.com.

2 Técnico em Administração/Univap, Brasil. E-mail: anna.clara5s@icloud.com.

3 Técnico em Administração/Univap, Brasil. E-mail: heloisamorais@live.com.

4 Técnico em Administração/Univap, Brasil. E-mail: erica.reis@univap.br.
} 